УДК 902/904

ДИСКУССИЯ О «НОВОМ МЕДНОКАМЕННОМ» ВЕКЕ ЛЕСОСТЕПНОГО ПОДОНЬЯ

\author{
(c) 2020 В.В. Ставицкий
}

Пензенский государственный университет

Статья поступила в редакцию 19.07.2020

\begin{abstract}
Статья посвящена дискуссии о процессах взаимодействия населения неолитических и энеолитических культур в бассейне Верхнего и Среднего Дона. А.Т. Синюк рассматривал эти процессы в рамках «пережиточного неолита», А.М. Скоробогатов и А.В. Сурков предлагают их выделить в особый нео-энеолитический этап. Использование нового термина не решает проблемы и не способствует лучшему пониманию ситуации. Находок металла на поселенческих памятниках лесостепного Подонья нет, а исследованные погребения малочисленны. Топография среднестоговских памятников не отличается от расположения местных неолитических стоянок. Остеологические материалы с верхнедонских поселений Васильевский кордон 17 и 27 свидетельствуют, что ведущее место в хозяйстве энеолитического населения занимала охота и рыбная ловля. А на среднедонской стоянке Черкасская 5 домашние животные были известны уже в эпоху неолита. Слои со среднестоговской керамикой обычно залегают на тех же памятниках, что и неолитические материалы. Обязательным условием бесконфликтного сосуществования различных групп населения в пределах ограниченной территории является ориентация на разные источники получения пищи, связанная с освоением различных природно-хозяйственных ресурсов. В Подонье не было условий для параллельного развития населения с разными хозяйственно-экономическими укладами. Мигранты и аборигены вступали в тесные контакты друг с другом, что нашло отражение в появлении гибридных керамических материалов. Описанные процессы представляют собой частный случай перехода от века камня к эпохе металла, содержание которого полностью соответствует определению энеолита.

Ключевые слова: «пережиточный неолит», нео-энеолитический этап, лесостепное Подонье, среднестоговская культура, меднокаменный век, культура ямочно-гребенчатой керамики, ксизовский тип памятников, производящее хозяйство, миграция, радиоуглеродная хронология.
\end{abstract}

DOI: $10.37313 / 2658-4816-2020-2-3-96-102$

В последнее время мною был опубликован ряд статей и подготовлено два выступления на конференциях по вопросу о критериях выделения энеолитической эпохи на материалах лесостепных памятников Волго-Донского бассейна ${ }^{1}$, которые неизменно вызывали дискуссии среди участников. А недавно А.М. Скоробогатов и А.В. Сурков опубликовали статью с критикой ряда моих положений и аргументацией своих ${ }^{2}$.

Следует отметить, что данная тема для меня не нова, и я обращался к ней ранее, критикуя отдельные положения гипотезы А.Т. Синюка о длительном сосуществовании неолитических и

Ставицкий Владимир Вячеславович, доктор исторических наук, профессор кафедры всеобщей истории и обществоведения.

E-mail: stawiczky.v@yandex.ru энеолитических культур в Подонье, которое рассматривалось им в рамках «пережиточного неолита» ${ }^{3}$. К сожалению, критика была оставлена Арсеном Тиграновичем без внимания, хотя мои взгляды были ему достаточно хорошо известны, поскольку им был подготовлен отзыв на мою докторскую диссертацию ${ }^{4}$.

Отрадно, что именно А.М. Скоробогатов и А.В. Сурков, являющиеся учениками А.Т. Синюка, сочли возможным вступить в дискуссию и рассмотреть мои аргументы в указанной выше статье. Как и положено настоящим ученикам, они пошли дальше своего учителя и отказались от термина «пережиточный неолит» как потерявшего свою актуальность в пользу новогостарого термина нео-энеолит, определяя его в качестве периода сосуществования населения 
неолитических и энеолитических культур на одной и той же территории ${ }^{5}$.

В какой-то степени данное решение можно считать компромиссным в нашей дискуссии, но этот термин мне не нравится еще больше, чем прежний, поскольку несет на себе оттенок оксюморона. Во-первых, он образован с нарушением правил русского языка, из двух сложносоставных слов. От одного слова была взята только первая часть, а второе слово - полностью. Если перевести его на русский язык, то получится «ново-меднокаменный век». Во-вторых, закономерности исторического развития таковы, что при смене двух разных эпох и общественно-политических формаций наряду с передовыми новациями, которым принадлежит будущее, всегда сохраняются отживающие свой век традиции. Если исходить из логики сторонников выделения особого нео-энеолитического периода, то тогда следовало бы выделить и особый феодало-капиталистический этап. Однако историками почему-то этого до сих пор не сделано. Также возникает вопрос, а к какому этапу следует относить период сосуществования европейских колонизаторов с аборигенами Америки? Уровень развития европейцев по археологической периодизации соответствовал железному веку, аборигены Центральной Америки жили в медном веке, а Северной и Южной - в каменном. К железно-каменному и медно-железному? И почему до сих пор не выделен особый медно-бронзовый этап, ведь производство металлических изделий в ряде культур раннего бронзового века базировалось исключительно на меднорудной основе? Однако исследователями эпохи бронзы данный факт игнорируется и эпохальный статус культуры определяется по принадлежности к той или иной металлургической провинции.

Как ни странно, ответ на поставленный вопрос достаточно прост. Этого не делается потому, что у исследователей не возникает надобности в словесной эквилибристике, если достаточно хорошо ясна суть изучаемых процессов, и, напротив, нужда в новой терминологии выходит на первый план, когда не особенно понятно, а о чем же, собственно говоря, идет речь. Если в эпоху Левенка - Синюка одним из основных ин- струментов археологического познания реальности выступала интерпретация обобщенных данных, то в эпоху Суркова - Скоробогатова настало время разобраться в деталях проблемы.

В чем же заключалась суть процессов, происходивших в лесостепном Подонье в финале каменного века? Сначала рассмотрим аргументацию оппонентов и их критику в мой адрес. По мнению А.М. Скоробогатова и А.В. Суркова, в позднем неолите здесь появляются новые керамические типы и культуры - черкасский тип керамики, дронихинская культура, ксизовский тип керамики, однако совместное бытование в рамках одной территории населения с различными типами и уровнями хозяйства (имеется в виду местное население, оставшееся на «неолитической» стадии развития, и пришлое, «энеолитическое») никем из исследователей региона не ставится под сомнение 6 . Однако отсутствие сомнений у местных исследователей региона еще не означает истинности их взглядов, поэтому следует обратиться к фактам.

Итак, какие имеются доказательства того, что местное население действительно осталось на неолитической стадии развития, а пришлое пожинало плоды энеолитического прогресса? В связи с чем возникает вопрос, а что именно было характерно для этой предшествующей стадии? Прямой информации в статье оппонентов об этом нет, но из общего контекста можно понять, что, как и А.Т. Синюк, к неолитическим признакам они относят присваивающее хозяйство, отсутствие на памятниках металла, сохранение местных керамических традиций и развитие традиций лесных неолитических культур, влияние которых в этот период становится особенно ощутимым.

Следует отметить, что в настоящее время имеются данные о том, что неолитическое население Среднего Дона уже было знакомо с навыками разведения домашних животных. Coгласно определениям Е.Б. Яниш, в двух нижних слоях стоянки Черкасская 5 половина костей млекопитающих животных принадлежит одомашненным видам ${ }^{7}$. Исследователи стоянки допускают возможность, что все кости домашних животных могут быть связаны с энеолитическими материалами ${ }^{8}$. Однако в нижнем слое памят- 
ника вместе с остеологическими материалами встречается только керамика неолитического облика, которая на стоянке преобладает (297 фрагментов), тогда как энеолитическая - представлена всего 5 фрагментами. Поэтому их связь с неолитическим периодом весьма вероятна.

С другой стороны, по наблюдениям A.M. Скоробогатова и А.В. Суркова, кости домашних животных встречаются на нео-энеолитических памятниках Среднего Подонья, где зафиксированы фаунистические остатки ${ }^{9}$, т.е. местное население не только «переживает» свои прежние неолитические традиции, но и перенимает энеолитические новации.

Следующим энеолитическим признаком служит наличие находок меди. На неолитических памятниках лесостепного Дона их нет, однако указанные памятники представлены поселенческими комплексами, находки металла в которых крайне редкое явление. Неизвестны до сих пор металлические изделия и на энеолитических поселениях региона. Следовательно, названный критерий в данной ситуации не работает.

Можно ли говорить о сохранении в данный период местных неолитических навыков в производстве керамики? Видимо, да. Часть их сохраняется, наряду с ними получают распространение традиции изготовления ямочно-гребенчатой керамики лесного облика. Не располагая остеологическими материалами с неолитических памятников, А.Т. Синюк ставил знак равенства между сохранением керамических традиций и сохранением прежних способов получения пищи ${ }^{10}$. Для того времени подобная гипотеза представлялась допустимой, однако теперь появились данные, которые противоречат предположению А.Т. Синюка.

Совместное сосуществование населения с разными хозяйственными укладами на одной и той же территории, конечно, возможно. Однако обязательным условием длительного сосуществования данных групп населения является преимущественная ориентация на разные источники получения пищи, связанная с освоением различных природно-хозяйственных ресурсов. Если это условие выполняется, контакты между ними имеют ограниченный характер, что позволяет этим группам сохранять достаточно продолжительное время свой этнокультурный облик и хозяйственно-экономические приоритеты. На мой взгляд, подобных условий в указанный хронологический период на лесостепной территории Подонья не было.

Одним из показателей различной хозяйственной занятости населения является топографическое расположение памятников. В моей статье в качестве примера, свидетельствующего о скотоводческой специализации населения, были рассмотрены особенности топографии памятников срубной культуры, приуроченных к водораздельным пространствам и небольшим водотокам, не представляющим значительного интереса для аборигенов, ориентированных на занятие рыболовством. По мнению А.М. Скоробогатова и А.В. Суркова, мною была допущена ошибка, поскольку в монографии А.Т. Синюка, на которую в статье дана ссылка, говорится только о погребальных памятниках, достаточно равномерно рассеянных по всей территории Верхнего и Среднего Дона ${ }^{11}$.

Необходимо признать, что приведенная мной ссылка не является безупречной. Однако мои оппоненты, выдвигая утверждение о том, что «в Донской лесостепи срубные поселенческие памятники гораздо чаще располагаются там же, где и стоянки неолита», вообее не приводят ссылок на публикации, подтверждающих их правоту. Не являясь специалистом по срубной культуре Подонья, я не смог найти карту, на которую были бы нанесены именно поселенческие памятники. Однако, как указано в другой книге А.Т. Синюка: «обширные курганные могильники срубных племен, как правило, располагаются недалеко от долговременных поселков, за рекой на водораздельных участках» ${ }^{12}$.

Еще более определенно А.Т. Синюк о топографии срубных поселений высказывается в другой своей работе, где он пишет: «Можно со всей определенностью считать, что ни в поймах, ни на низких участках надпойменных террас стационарные поселки не создавались. Но именно здесь, в условиях высокой влажности, в приустьевых местах рек и проток с богатой озерноболотной растительностью, были оптимальные условия для ведения сетевого и запорного рыболовства, охоты на дичь, а также для осуществле- 
ния выпаса скота и использования плодородных лессовых отложений пойм в земледельческом хозяйстве (прежде всего в огородничестве). Таким образом, на низких участках возможно наличие остатков только сезонных промысловых стоянок и могильников кратковременного использования, тогда как стационарные поселки и племенные могильники размещались на более высоких участках долин» ${ }^{13}$.

Следует отметить, что хорошо известная мне территория Пензенской области тоже относится к ареалу лесостепных древностей срубной культуры. Срубные поселения здесь преимущественно расположены на черноземных почвах и приурочены к небольшим водотокам ${ }^{14}$. Не думаю, что на Дону существовала какая-то особая срубная культура, большая часть населения которой, как и обитатели местных неолитических и энеолитических стоянок, была связана с поймами крупных рек. Наличие на ряде неолитических стоянок слабо насыщенных слоев со срубной керамикой не идет ни в какое сравнение с фактами совместного залегания представительных материалов неолитических и энеолитических культур.

Симптоматично, что данный тезис в целом разделяется А.М. Скоробогатовым и А.В. Сурковым, которые относят срубные памятники, расположенные в тех же топографических условиях, что и неолитические поселения, к разряду сезонных кратковременных стоянок. Однако данная закономерность не распространяется на среднестоговские памятники, поскольку их долговременные поселения располагаются в тех же местах, что и неолитические. Но главное заключается в том, что среднестоговских памятников нет на малых водотоках, где расположены долговременные срубные поселения, следовательно, ими использовалась та же экологическая ниша, что и неолитическими аборигенами. В отличие от срубных племен, для выпаса своего скота им вполне хватало пойменных угодий. Таким образом, аргументация А.М. Скоробогатова и А.В. Суркова только подтверждает мой тезис о различной хозяйственной направленности среднестоговской и срубной культур. Срубники с местными рыболовами и охотниками большую часть года при добывании пищи не конкурировали, чего нельзя сказать о среднестоговцах.
Впрочем, топография памятников все же является косвенным показателем экономической занятости населения. Между тем имеются прямые данные, которые свидетельствуют, что хозяйственная деятельность неолитического и энеолитического населения на Дону была ориентирована на одни и те же источники добывания пищи. К такому выводу фактически пришли исследователи поселения Васильевский кордон 27 , отметив, что главным занятием энеолитического населения памятника по-прежнему оставалась охота и рыбная ловля, скотоводство же не играло существенной роли ${ }^{15}$, а в энеолитическом слое Васильевского кордона 17 ими зафиксированы только кости диких животных ${ }^{16}$.

Аргументируя свою точку зрения, А.М. Скоробогатов и А.В. Сурков обращаются к материалам поселения Ямное, которые, по их мнению, иллюстрируют картину сосуществования местного неолитического населения и пришлого среднестоговского ${ }^{17}$. При анализе радиоуглеродных дат они констатируют более ранний возраст комплексов позднего неолита (четыре даты, от 3950-3350 ВС до 3710-3360 ВС) по сравнению со среднестоговской посудой (две даты, 3650-3300 ВС и 3550-2900 ВС $)^{18}$. Следует отметить, что в монографической публикации эти даты охарактеризованы теми же авторами как «противоречащие имеющимся построениям как по неолиту, так и энеолиту региона» ${ }^{19}$. Это действительно так, иногда даты, полученные по керамике с одного памятника, характеризуются явными отклонениями в хронологии, и убедительного объяснения этому факту до сих пор не найдено ${ }^{20}$.

Недостоверность указанных дат подтверждается и характером залегания керамики различных культур на памятнике, максимум распространения которых приходится на одни и те же слои. Как отмечено в монографии: «Очень часто фрагменты керамики разных эпох перекрывали друг друга, а развалы лежали на одной глубине. Это может указывать на определенную хронологическую близость комплексов неолита и энеолита, если не сказать больше - их совместное бытование. Тем более что в керамическом инвентаре прослеживаются признаки взаимовлияния» ${ }^{21}$. На мой взгляд, подобное стратиграфическое залегание материала свидетельствует именно о совместном про- 
живании на поселении Ямное представителей разных керамических традиций, степень сходства которых столь велика, что при определении эпохальной принадлежности материалов авторы раскопок ориентируются исключительно на примеси в тесте керамики, поскольку другие параметры у ряда сосудов практически совпадают. Например, явный энеолитический облик имеет продатированный венчик сосуда, характеризующийся раструбовидным горлом. Причем он имеет наиболее раннюю дату из всей керамики памятника $4960 \pm$ 90 BP (3970-3630 ВC $)^{22}$.

Скорее всего, не вся неолитическая керамика поселения Ямное синхронна энеолитической. По-видимому, среднестоговское население появилось здесь позже и либо вытеснило аборигенов с обжитых мест, либо инкорпорировало в состав своей общины. В любом случае облик данных материалов свидетельствует о тесных процессах взаимодействия, в ходе которого местное неолитическое население наверняка восприняло не только культурные, но и хозяйственные традиции пришельцев. Следовательно, гипотеза о длительном и автономном сосуществовании двух разных укладов - неолитического и энеолитического - не находит подтверждения. Для ее актуализации необходимы данные, свидетельствующие о параллельном существовании различных традиций на протяжении значительного отрезка времени, что не подтверждается материалами радиоуглеродного датирования. Без учета некорректных дат поселения Ямное неолитические памятники завершают свое существование на грани 4782-4320 BC ${ }^{23}$, а самая ранняя дата из среднестоговского слоя стоянки Черкасская 3 датируется временем 4760-4345 $\mathrm{BC}^{24}$, что может свидетельствовать о хронологическом смыкании данных традиций. Как видим, период их сосуществования находится в пределах измерительной погрешности радиоуглеродного метода.

В качестве примера более поздней хронологии неолитических памятников в сравнении с энеолитическими А.М. Скоробогатов и А.В. Сурков приводят стратиграфию стоянки Дрониха, где скорченные на спине погребения, совершенные по среднестоговской погребальной обрядности, были перекрыты неолитической постройкой с полом, утрамбованным битой раковиной 25 . Однако следует иметь в виду, что полом постройки было перекрыто только одно из шести погребений, отнесенных А.Т. Синюком к среднестоговским. Все они безынвентарные, поэтому вопрос об их культурной принадлежности не столь однозначен. Причем погребение №18 было совершено с глубины 45 см, что соответствует верхнему уровню неолитической постройки, значит, оно могло быть совершено одновременно с ней.

При этом столь необычная стратиграфия не является свидетельством поздней хронологии неолитических материалов Дронихи. Поскольку по керамике дронихинского типа с поселения получена радиоуглеродная дата 4850-4490 BC 26 , следовательно, накольчатая керамика, фрагменты которой преобладали в заполнении постройки, должна относиться к еще более раннему времени. Получается, что время совершения дронихинских погребений должно соответствовать раннему этапу среднестоговской культуры. Однако материалы раннестоговского времени на Среднем Дону малочисленны и их появление здесь носит спорадический характер. В диссертации А.М. Суркова к раннестоговским отнесены всего три стоянки Среднего Дона, с которых получены незначительные материалы ${ }^{27}$. Поэтому неправомерно ставить вопрос о длительном сосуществовании на данной территории неолитического и раннестоговского населения. Скорее это были сезонные миграции небольших групп населения степной зоны, которые не оставили после себя заметных следов взаимодействия с аборигенами.

В статье А.М. Скоробогатова и А.В. Суркова территория лесостепного Дона рассматривается в качестве единого региона, характеризующегося общими тенденциями развития, в рамках взаимодействия неолитических и энеолитических культур. Между тем анализ остеологических материалов свидетельствует о том, что на памятниках Среднего Дона элементы производящего хозяйства получают распространение уже в эпоху неолита, а на Верхнем Дону и в энеолитическое время продолжают господствовать присваивающие отрасли. Достаточно разнонаправленный характер носит в этих регионах и развитие керамических традиций. В частности, на Верхнем Дону в ре- 
зультате интенсивного взаимодействия местных и пришлых культур происходит сложение памятников ксизовского типа, чего не наблюдается на территориях, расположенных южнее.

По мнению А.М. Скоробогатова и А.А. Суркова, выделение особого нео-энеолитического этапа в лесостепном Подонье согласуется с принципами периодизации неолитических и энеолитических культур Д.Я. Телегина, который использует при ее построении аналогичную терминологию ${ }^{28}$. Однако это не так. У Д.Я. Телегина период сосуществования неолитических и энеолитических культур практически исчерпывается первым этапом его периодизации, на котором в Поднепровье фиксируется совместное бытование памятников раннетрипольской культуры и неолитических культур днепро-донецкой общности. Уже на втором, среднетрипольско-среднестоговском этапе его периодизации, который датируется 4500-3800 ВС 29 , фактически наблюдается сосуществование только энеолитических культур. Поскольку из неолитических культур днепро-донецкой общности лишь самые поздние памятники донецкой культуры (4698-4243 $\mathrm{BC})^{30}$ можно отнести к началу данного хронологического отрезка. Данная периодизация была разработана Д.Я. Телегиным в то время, когда практически не имелось радиоуглеродных дат по культурам днепро-донецкой общности, появление которых показало несостоятельность заложенных в ее основу принципов.

Логика выделения особого неолитическоэнеолитического этапа, видимо, продиктована потребностью в особом переходном периоде от века камня к эпохе металла. Однако именно для этих целей и был выделен меднокаменный век, соединяющий в себе черты двух сопредельных эпох. А сосуществование на одной и той же территории населения с двумя разными экономическими укладами представляет собой частный случай подобного перехода от одной эпохи к другой. Это и есть энеолит.

\section{ПРИМЕЧАНИЯ}

${ }^{1}$ Ставицкий B.B. К вопросу о выделении неоэнеолитической эпохи в Поволжье // Археологические источники и культурогенез. Проблемы периодизации и хронологии в археологии эпохи раннего металла Восточной Европы. Ма- териалы тематической научной конференции. Е.А. Черленок (отв. редактор), В.С. Бочкарев, А.И. Мурашкин. СПб., 2013. С. 31-33; Ставицкий B.B. К вопросу о «пережиточном неолите» лесостепного Дона // Самарский научный вестник. 2019. Т. 8. № 2 (27). С. 239-243; Ставицкий B.B. Концепция «пережиточного неолита» А.T. Синюка // Эволюция неолитических культур Восточной Европы. Материалы международной конференции, посвященной 120-летию М.Е. Фосс, 110-летию Н.Н. Гуриной и 80-летию А.Т. Синюка. Под редакцией А.А. Выборнова, Е.В. Долбуновой, Е.М. Колпакова, Е.С. Ткач. СПб., 2019. С. 85-86.

${ }^{2}$ Скоробогатов А.М., Сурков А.В. Финал каменного века в лесостепном Подонье: пережиточный неолит или нео-энеолит // Известия Самарского научного центра Российской академии наук. Исторические науки. Т. 2. № 1. Самара, 2020. С. 85-93.

${ }_{3}^{3}$ Ставицкий B.B. Динамика взаимодействия социумов лесной и степной зон на территории Волго-Донского междуречья в древности // Известия Пензенского государственного педагогического университета им. В.Г. Белинского. 2007. № 8. С.134.

${ }^{4} \mathrm{~K}$ сожалению, когда один из моих оппонентов заболел и не смог принять участие в заседании диссертационного совета, отзыв А.Т. Синюка выпал из процесса защиты диссертации, поскольку он отказался приехать в Ижевск, защита была перенесена, и состав оппонентов изменился.

${ }^{5}$ Скоробогатов А.М., Сурков А.В. Указ. соч. С. 86. 6 Там же.

${ }^{7}$ Скоробогатов А.М., Яниш Е.Ю., Александровский А.Л. Неолитическая стоянка Черкасская-5 на Среднем Дону. Соотношение охоты и рыболовства по фаунистическим и археологическим данным // Стратегии жизнеобеспечения в каменном веке, прямые и косвенные свидетельства рыболовства и собирательства. 2018. Т. 50. С. 72-75.

${ }^{8}$ Скоробогатов A.M. Стоянка Черкасская-5 и ее место в раннем неолите Среднего Дона // Caмарский научный вестник. 2018. Т. 7. № 3 (24).

${ }^{9}$ Скоробогатов А.М., Сурков А.В. Указ. соч. С. 87.

${ }^{10}$ Синюк А.T. Население бассейна Дона в эпоху неолита. Воронеж, 1986. С. 153-164.

${ }^{11}$ Синюк А.Т. Бронзовый век бассейна Дона. Воронеж: Издательство Воронежского педуниверситета, 1996. С. 226.

${ }^{12}$ Винников А.З., Синюк А.Т. По дорогам минувших столетий. Воронеж, 1990. С. 135.

${ }^{13}$ Синюк A.T. Периодизация срубной культуры Среднего Дона (по материалам погребальных памятников) // Избранные труды. Воронеж, 2014. С. 289.

${ }^{14}$ Ставицицй B.B. Срубные памятники Пензенского Примокшанья // Нижневолжский археологический вестник. 2001. № 4. С. 44-57.

${ }^{15}$ Смольянинов Р.В., Юркина Е.С., Яниш Е.Ю., Желудков А.С., Шеменев С.В., Соловьев А.В. Энео- 
литическое поселение и могильник Васильевский кордон 27: свидетельства охоты и рыбной ловли (исследования 2016-2018 годов, предварительная публикация) // Самарский научный вестник. Самара, 2019. Т. 9. № 4 (29). С. 122-130.

${ }^{16}$ Смольянинов Р.В., Яниш Е.Ю., Свиридов А.А. Верхнедонское поселение Васильевский кордон 17 сооружение 4 // Неолитические культуры Восточной Европы: хронология, палеоэкология, традиции. СПб., 2015. С. 124-129.

${ }^{17}$ Скоробогатов А.М., Сурков А.В. Указ. соч. С. 87-89.

18 Там же.

${ }^{19}$ Сурков А.В., Скоробогатов А.М. Многослойная стоянка Ямное (Материалы исследований). Воронеж, 2012. С. 66-67.

${ }^{20}$ Ставицкий В.В. Статистическая модель радиоуглеродной хронологии неолитических памятников лесостепного Заволжья // Самарский научный вестник. Самара, 2018. Т. 7. № 4 (25). С. 204-210.

${ }^{21}$ Сурков А.В., Скоробогатов А.М. Указ. соч. С. 10.

22 Там же. С. 49. Рис. 34.

${ }^{23}$ Выборнов А.А., Кулькова М.А., Ойнонен М., Посснерт $\Gamma$. Новые радиоуглеродные даты неолитических памятников Подонья // Известия Самарского научного центра Российской академии наук. 2017. Т. 19. № 3. Ч. 2. С. 366-369.
${ }^{24}$ Скоробогатов А.М., Сурков А.В. Указ. соч. С. 89.

${ }^{25}$ Синюк А.Т. Об энеолитических могильниках лесостепи (по материалам Дона) // СА. 1984. № 3. С. 105.

${ }^{26}$ Скоробогатов А.М., Смольянинов Р.В., Сурков A.B., Ойнонен M., Посснерт Г. Хронология неолитических памятников лесостепного Подонья // Радиоуглеродная хронология эпохи неолита Восточной Европы VII-III тысячелетия до н.э. / Сост. Г.И. Зайцева, О.В. Лозовская, А.А. Выборнов, А.Н. Мазуркевич. Смоленск: Свиток, 2016. С. 244-260.

${ }^{27}$ Скоробогатов А.M. Энеолитические памятники Донской лесостепи: автореф. дисс. ... канд. ист. наук. Воронеж: Воронежский государственный университет, 2011. С. 14.

${ }^{28}$ Телегин Д.Я. О хронологии и периодизации культур неолита и медного века Юго-Запада Восточной Европы. Понятие о нео-энеолитическом времени региона // Проблемы хронологии и этнокультурных взаимодействий в неолите Евразии (хронология неолита, особенности культур и неолитизация регионов, взаимодействия неолитических культур в Восточной и Средней Европе). СПб.: ИИМК РАН, 2004. С. 106-121.

${ }^{29}$ Там же. С. 115.

${ }^{30}$ Котова Н.С. Древнейшая керамика Украины. Киев; Харьков: Майдан, 2015. С. 50.

\title{
DISCUSSION OF THE «NEW ENEOLITHIC» CENTURY IN THE FOREST-STEPPE DON REGION
}

\author{
(c) 2020 V.V. Stavitsky \\ Penza State University
}

\begin{abstract}
The article is devoted to the discussion of the processes of interaction between the population of Neolithic and Eneolithic cultures in the Upper and Middle Don basin. A.T. Sinyuk considered these processes within the framework of «Neolithic survival», A.M. Skorobogatov and A.V. Surkov propose to single them out into a special Neo-Eneolithic stage. The use of the new term does not solve the problem and does not contribute to a better understanding of the situation. There are no metal finds on the settlements of Don forest-steppe area, and the studied burials are few. The topography of the Sredny Stog settlements does not differ from the location of local Neolithic sites. The osteological materials from the Upper Don settlements named Vasilyevsky cordon 17 and 27 indicate that the leading place in the Eneolithic economy was occupied by hunting and fishing. And at the Middle Don settlement of Cherkasskaya 5 domestic animals were known already in the Neolithic Age. The layers with Sredny Stog`s pottery are usually found on the same monuments as Neolithic materials. A prerequisite for the conflict-free coexistence of different groups within a limited area is their orientation towards different sources of food, connected with the development of different natural and economic resources. There were no conditions for the parallel development of the population with different economic and social patterns in the Don region. Migrants and aborigines came into close contact with each other, which was reflected in the emergence of hybrid ceramic materials. The processes described above represent a particular case of transition from the stone age to the metal age, the content of which fully corresponds to the definition of Eneolithic.

Keywords: «relics of Neolithic», Neo-Eneolithic stage, forest-steppe Don region, Sredny Stog culture, Eneolithic, Pit and Crank ceramics culture, Xyzov type of settlements, producing farm, migration, radiocarbon chronology.
\end{abstract}

DOI: $10.37313 / 2658-4816-2020-2-3-96-102$

Vladimir Stavitsky, Doctor of History, Professor, Department of General History and Social Sciences. E-mail: stawiczky.v@yandex.ru 